\title{
Terpenoids from a multiple shoot culture of Telekia speciosa
}

\author{
Anna Stojakowska*, Janusz Malarz, Wanda Kisiel \\ Institute of Pharmacology, Polish Academy of Sciences, Smętna 12, 31-343 Kraków, Poland
}

\begin{abstract}
Multiple shoots of Telekia speciosa were cultivated on MS medium containing $4.44 \mu \mathrm{M}$ BAP and $0.54 \mu \mathrm{M}$ NAA, solidified with agar. After eight weeks of culture the shoots were harvested and extracted with methanol. From the methanol extract one pseudoguaianolide - 2,3-dihydroaromaticin and three thymol derivatives: 8-hydroxy-9,10-diisobutyryloxythymol, 10-isobutyryloxy-8,9-epoxythymyl isobutyrate and 10-(2-methylbutyryloxy)-8,9-epoxythymyl isobutyrate were isolated as major secondary metabolites. Moreover, the shoots produced megastigmane and monoterpene glucosides, which were isolated for the first time from the species. The content of 2,3-dihydroaromaticin in the shoot culture was similar to that found in the intact plant, whereas yields of the three thymol derivatives were higher from multiple shoots than from the plants grown in the open field.
\end{abstract}

Keywords: megastigmane, monoterpene, multiple shoots, sesquiterpene lactone, Telekia speciosa

\section{Introduction}

Heartleaf oxeye [Telekia speciosa (Schreb.) Baumg., Asteraceae, tribe Inuleae, basionym - Buphtalmum speciosum Schreb.] is a perennial plant native to Southeastern Europe and Asia Minor. It is the only species belonging to the genus Telekia Baumg. [1], which, accordingly to recent molecular phylogenetic studies based on both cpDNA and ITS sequence analysis [2] is closely related to Carpesium spp. and a group of resiniferous taxa of Inula L., including Inula helenium - a well known medicinal plant. Likewise the roots of the resiniferous Inula species, roots of T. speciosa contain essential oil with eudesmane-type sesquiterpene lactones as major constituents. Except for sesquiterpene lactones of eudesmanolide and pseudoguaianolide type, the plant reportedly contains xanthanolides, terpenoid cyclopropenone derivatives, polyacetylene, thymol and nerol derivatives [3-6]. Data on medicinal uses of T. speciosa are sparse, however, biological activity of secondary metabolites produced by the plant have gained some interest. Except for widely investigated alantolactone and isoalantolactone, other sesquiterpene lactones - telekin and 2,3-dihydroaromaticin have also shown marked antiproliferative activity against human cancer cell lines in vitro $[7,8]$. Moreover, 2,3-dihydroaromaticin is a potent inhibitor of lipopolisaccharide induced nitric oxide synthesis and a moderate inhibitor of the transcription factor NF- $\kappa \mathrm{B}$ activation $[9,10]$.

* Corresponding author. Email: stoja@if-pan.krakow.pl

This is an Open Access digital version of the article distributed under the terms of the Creative Commons Attribution 3.0 License (creativecommons.org/licenses/ by/3.0/), which permits redistribution, commercial and non-commercial, provided that the article is properly cited.

(c) The Author(s) 2011 Published by Polish Botanical Society
Telekin affected activity of some antioxidant and drug-metabolizing enzymes in rat liver and kidney $[11,12]$. In a recently published report on antiproliferative and direct cytotoxic activity of extracts from T. speciosa an interference of these preparations with cell proliferation in vitro has been proven [13].

The aim of the present study was to achieve in vitro multiplication of T. speciosa shoots and to investigate secondary metabolism of the culture as a potential source of biologically active compounds.

\section{Material and methods}

\section{Plant material}

Seeds of Telekia speciosa (Schreb.) Baumg. were delivered by Botanical Garden in Nantes (France). Multiple shoots of the plant were collected from in vitro cultures maintained in our laboratory. As a reference material, aerial parts of Telekia speciosa (Schreb.) were harvested in July-August from plants grown in the Garden of Medicinal Plants, Institute of Pharmacology, Polish Academy of Sciences, Kraków, where a voucher specimen $(10 / 08)$ was deposited. The plants were obtained by acclimatization of in vitro regenerated plantlets and were collected in the second year of their vegetation outside.

\section{Multiple shoot culture}

An in vitro shoot culture of T. speciosa was derived by inoculation of nodal explants excised from aseptic seedlings onto a solidified (0.8\% agar) MS nutrient medium [14], containing $3 \%$ sucrose, $4.44 \mu \mathrm{M}$ BAP and $0.54 \mu \mathrm{M}$ NAA, with $\mathrm{pH}$ adjusted to 5.8 , before autoclaving $\left(20 \mathrm{~min}\right.$ at $\left.121^{\circ} \mathrm{C}\right)$. The culture was maintained in baby food jars (Sigma, USA) covered with Magenta B-caps (Sigma, USA), under continuous illumination $\left(40 \mu \mathrm{mol} \mathrm{m} \mathrm{m}^{-2}\right)$, at $25 \pm 3^{\circ} \mathrm{C}$. Four explants per culture vessel were inoculated. After eight weeks of cultivation, the multiplied 
shoots were harvested, dried and used for phytochemical analysis. Some of the in vitro regenerated shoots were also used as a starting material in the next multiplication cycle or were rooted on hormone free MS medium with reduced concentration of macronutrients $(1 / 2)$ and planted into the garden.

\section{Isolation of terpenoids from multiple shoots}

Dried and pulverized shoots (17 g) were exhaustively extracted with $\mathrm{MeOH}$ at room temperature. The extract was evaporated in vacuo providing an oily residue $(6 \mathrm{~g})$ which was subjected to column chromatography on silica gel (Merck, art. 7754) using hexane-EtOAc (up to $100 \%$ EtOAc) followed by EtOAc- $\mathrm{MeOH}$ (up to $10 \% \mathrm{MeOH}$ ) gradient solvent systems. Fractions eluted with hexane-EtOAc $(9: 1 \mathrm{v} / \mathrm{v})$ were further separated by semipreparative RP-HPLC on a Delta-Pak C18 cartridge column $(25 \times 100 \mathrm{~mm}$, particle size $-15 \mu \mathrm{m}$, Waters, Milford, MA) using $\mathrm{MeOH}-\mathrm{H}_{2} \mathrm{O}(13: 7 \mathrm{v} / \mathrm{v})$ as a solvent system (flow rate $-6 \mathrm{ml} \mathrm{min}^{-1}$ ) to give 18-hydroxy-9,10-diisobutyryloxythymol (2.1 mg, Rt - 36 min; Fig. 1a), 10-isobutyryloxy-8,9-epoxythymyl isobutyrate $(7.5 \mathrm{mg}, \mathrm{Rt}-64 \mathrm{~min}$; Fig. 1b) and 10-(2-methylbutyryloxy)-8,9-epoxythymyl isobutyrate $(4.0 \mathrm{mg}$, Rt - $99 \mathrm{~min}$; Fig. 1c). A Waters (Milford, MA, USA) model $600 \mathrm{E}$ solvent delivery system coupled to a Waters 2487 dual wavelength UV/VIS absorbance detector operating at $205 \mathrm{~nm}$ and $275 \mathrm{~nm}$ was employed. Fractions eluted from the conventional silica gel column by hexane-EtOAc (4:1 $\mathrm{v} / \mathrm{v}$ ) were further separated by preparative TLC on precoated silica gel plates (Merck, art. 5553) in a solvent system identical with that used in the column chromatography. The fractions yielded $30 \mathrm{mg}$ of 2,3-dihydroaromaticin (Fig. 1d). From the fractions eluted with EtOAc, roseoside (1.5 mg; Fig. 1e) and $6 \beta$-hydroxypiperitol-3-O- $\beta$-D-glucopyranoside $(1.5 \mathrm{mg}$; Fig. 1f) were isolated by means of semipreparative RP-HPLC, using $\mathrm{MeOH}-\mathrm{H}_{2} \mathrm{O}(2: 3)$ as a solvent system (flow rate $-3 \mathrm{ml}$ $\mathrm{min}^{-1}$ ). Retention times of the compounds were $28 \mathrm{~min}$ and $59.5 \mathrm{~min}$, respectively.

Structures of the isolated compounds were determined by comparison of their spectral data $(1 \mathrm{H} \mathrm{NMR}, 500.13 \mathrm{MHz}$ or 300.18 MHz; UV) with those found in the literature [4,5,1518 ] and those of the compounds isolated previously in our laboratory.

\section{Quantification of thymol derivatives}

Thymol derivatives were quantified by RP-HPLC as described elsewhere [19].

\section{Quantification of 2,3-dihydroaromaticin}

To the dry, pulverized plant material $(100 \mathrm{mg}) 50 \mu \mathrm{l}$ of a freshly prepared santonin solution $(0.5 \%$ in $\mathrm{MeOH})$ were added as an internal standard. The plant tissue was subsequently extracted with chloroform $(10 \mathrm{ml})$ at room temperature for $3 \mathrm{~h}$ on a gyratory shaker. The mixture was filtered and the residue was extracted once more with $5 \mathrm{ml}$ of a fresh solvent. The extracts were combined and evaporated to dryness under reduced pressure. The dry residue was redissolved in $0.75 \mathrm{ml}$ of $\mathrm{MeCN}$, diluted with $0.25 \mathrm{ml}$ of water, left to stand overnight at $4^{\circ} \mathrm{C}$ in the dark, and centrifuged (13000 rpm, 3 min) prior to HPLC analysis. Quantitative analysis of 2,3-dihydroaromaticin was performed by analytical RP-HPLC using an Agilent 1200 Series HPLC system (Agilent Technologies, USA) equipped with a Rheodyne manual sample injector, quaternary pump, degasser, column oven and a diode array detector. Chromatographic separations were carried out at $40^{\circ} \mathrm{C}$,

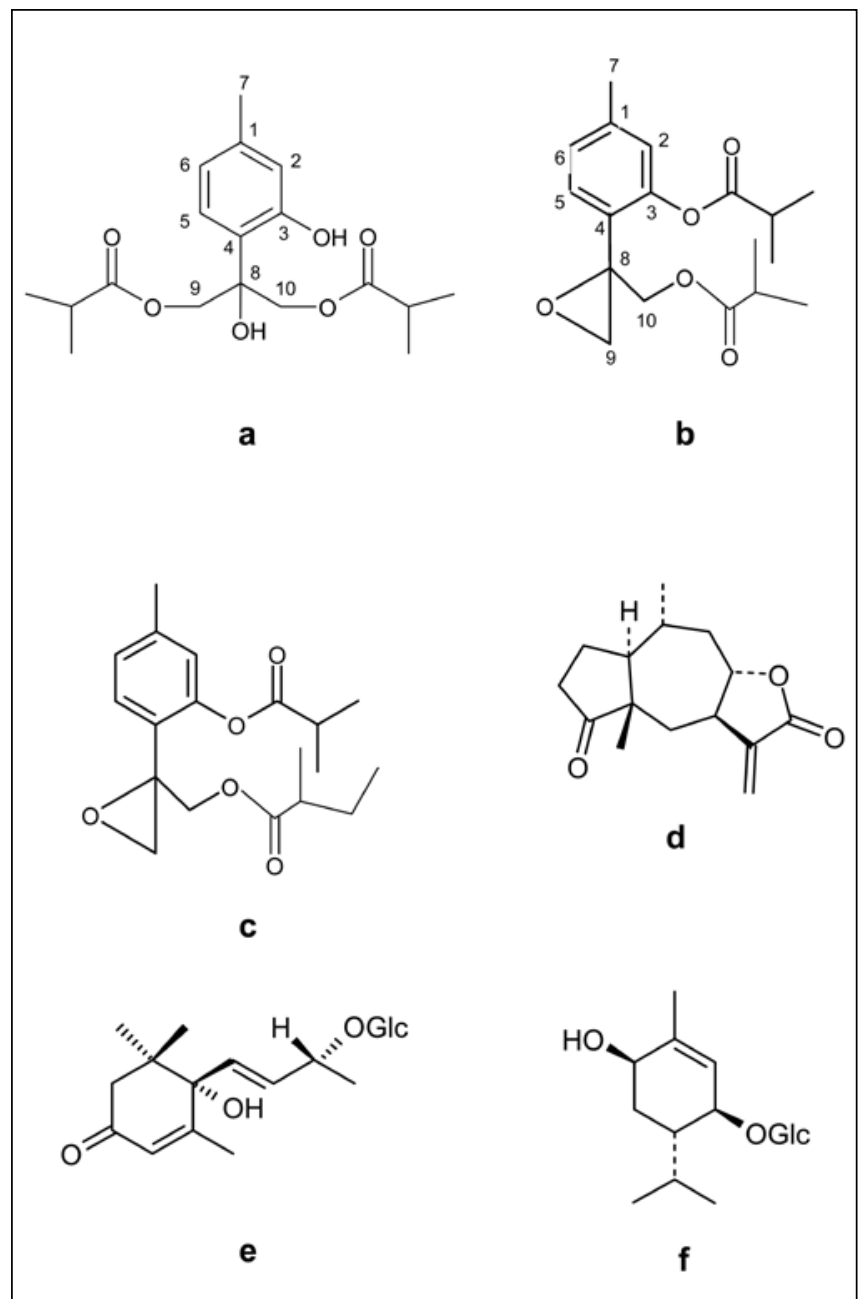

Fig. 1 Structures of terpenoids isolated from multiple shoot culture of Telekia speciosa: a 8-hydroxy-9,10-diisobutyryloxythymol; b 10-isobutyryloxy-8,9-epoxythymyl isobutyrate; c 10-(2-methylbutyryloxy)-8,9epoxythymyl isobutyrate; $\mathbf{d}$ 2,3-dihydroaromaticin; e roseoside; $\mathbf{f}$ $6 \beta$-hydroxypiperitol-3-O- $\beta$-D-glucopyranoside.

on a Purospher RP-18e column $(3 \times 125 \mathrm{~mm}, 5 \mu \mathrm{m}$ particle size; Merck KGaA, Germany) as described by Grass et al. [20]. The sample injection volume was $5 \mu$. The amount of 2,3-dihydroaromaticin was estimated by comparing the peak area obtained for this compound (detection wavelength $225 \mathrm{~nm}$ ) with the peak area obtained for the internal standard santonin.

\section{Statistics}

Results are presented as mean values $( \pm$ SD) derived from three independent experiments.

\section{Results and discussion}

The shoot multiplication medium applied in our experiment was reportedly used for in vitro propagation of Arnica montana [21]. Multiplcation rates achieved for T. speciosa were similar to those for A. montana, after initial month of culture (4-5 shoots per explant, see Fig. 2). A growth index of the culture, calculated as a ratio of a final fresh weight of an explant with regenerated shoots (after eight week culture) to a fresh weight of inoculum, reached 60 (Tab. 1). Extension of the culture cycle to eight weeks caused raise of T. speciosa multiplication rate to 11 . Moreover, the shoots 


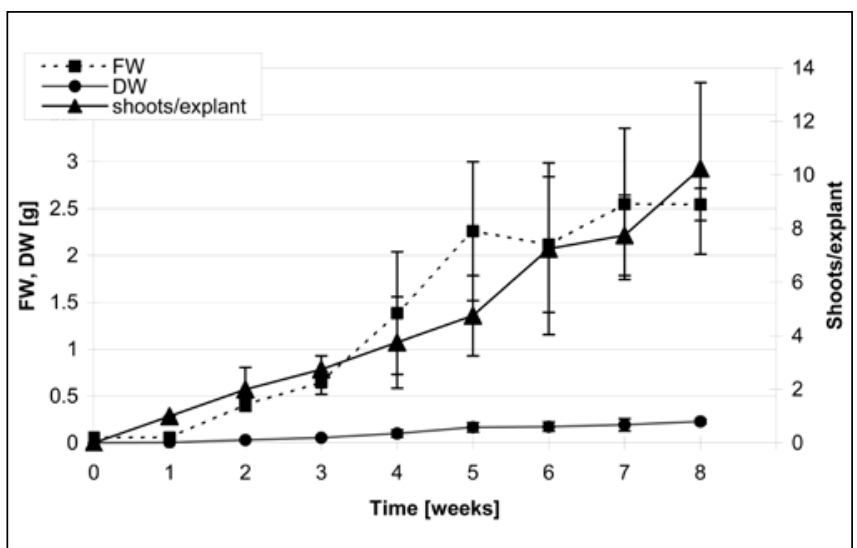

Fig. 2 Time course of biomass accumulation and axillary shoot proliferation in in vitro cultures of Telekia speciosa initiated from nodal explants. Bars represent standard deviation. FW - fresh weight; DW - dry weight.

harvested after eight week culture were longer and possessed well developed hirsute leaves. Six terpenoids were isolated from multiple shoots of T. speciosa. 10-Isobutyryloxy-8,9-epoxythymyl isobutyrate and 2,3-dihydroaromaticin were previously isolated from the plants of the species [4]. The remaining four compounds: 8-hydroxy-9,10-diisobutyryloxythymol, 10-(2-methylbutyryloxy)-8,9-epoxythymyl isobutyrate, roseoside, and $6 \beta$-hydroxypiperitol-3-O- $\beta$-D-glucopyranoside, to our knowledge, were found for the first time in the plant, though 10-isovaleryloxy-8,9-epoxythymyl isobutyrate - an isomer of 10-(2-methylbutyryloxy)-8,9-epoxythymyl isobutyrate and two thymol derivatives of unknown structure have been found recently in essential oil from aerial parts of T. speciosa [22].

Tab. 1 Axillary shoot proliferation from nodal explants of Telekia specios $a$ inoculated on solidified MS medium supplemented with 4.44 $\mu \mathrm{M}$ BA and $0.54 \mu \mathrm{M}$ NAA, after eight week of culture (data derived from ten consecutive passages $\pm \mathrm{SD}$ ).
Number of explants

Mean fresh weight of an explant (g)

Number of regenerated shoots ( $>1 \mathrm{~cm}$ long) per explant

Mean fresh weight of an explant with regenerated shoots (g) $\quad 3.5 \pm 1.3$
The yields of compounds from multiple shoots and plantlets in liquid medium were, however, five to ten times lower than those found in rooted plantlets grown on solidified media. In vitro grown plantlets of $A$. montana produced higher amounts of pseudoguaianolides than the parent plants. The contents of helenalin and its derivatives were particularily affected. The most abundant compound - helenalin methacrylate, constituted $0.32 \%$ of the dry weight of in vitro grown plantlets. The content $(0.27 \%$ dry weight) of 2,3-dihydroaromaticin in multiple shoots of T. speciosa seems to be encouraging to undertake attempts of the culture conditions optimization.

Tab. 2 Contents of 2,3-dihydroaromaticin (as\% dry weight \pm SD) in T. speciosa multiple shoots and leaves of the intact plant.

Plant material

2,3-Dihydroaromaticin

Multiple shoots after four week culture

$0.05 \pm 0.01$

Multiple shoots after eight week culture

$0.26 \pm 0.01$

Leaves of the plant

$0.22 \pm 0.01$

Thymol derivatives are common constituents of Inuleae plants. The contents of 8-hydroxy-9,10-diisobutyryloxythymol and the other thymol derivatives in the multiple shoots were higher than those in the intact plant (Tab. 3). This result is in agreement with our previous observation that juvenile tissues of Inula spp. accumulated higher amounts of the monoterpenoids than the mature plants do [19]. However, the yields of thymol derivatives from T. speciosa multiple shoots were much lower than those from root cultures of Inula spp. [19] and hairy roots of Arnica montana [25]. Thus, multiple shoot culture of T. speciosa seems to be of low interest as a thymol derivative producer.

The monoterpene glycoside - $6 \beta$-hydroxypiperitol-3O- $\beta$-D-glucopyranoside and roseoside - (6S,7E,9R)-6,9dihydroxymegastigma-4,7-dien-3-one are constituents of different Asteraceae plants, representatives of several tribes (e.g.: Cichorieae - [26,27]; Anthemideae - [28]; Eupatorieae [16]), but to our best knowledge their presence in Telekia and Inula spp. has not been reported yet.

In conclusion: multiple shoots of T. speciosa which accumulate terpenoids of interesting biological activities, produce 2,3-dihydroaromaticin in amount similar to that found in the leaves of the intact plant. Taking into consideration the

Pseudoguaianolide 2,3-dihydroaromaticin was the only sesquiterpene lactone produced by the culture, whereas several sesquiterpene lactones were reported from the aerial parts of the intact plant [3-5]. Its content in multiple shoots, after 8 week culture was similar to that in leaves of the intact plant. Probably due to the stage of morphological development, the multiple shoots harvested after eight week of culture accumulated higher amount of 2,3-dihydroaromaticin than that found in shoots after 4 week culture (Tab. 2). Pseudoguaianolides were also produced by multiple shoots [23] and in vitro grown plantlets of Arnica montana [23,24]. Multiple shoots cultivated on a solidified medium and plantlets grown in a liquid medium as well as in vitro cultivated rooted plantlets on solidified media, accumulated the same set of sesquiterpene lactones: helenalin, 11a,13-dihydrohelenalin and their esters.
Tab. 3 Contents of thymol derivatives (as \% dry weight \pm SD) in $T$. speciosa multiple shoots and leaves of the intact plant.

\begin{tabular}{lccc} 
Plant material & a & b & c \\
\hline $\begin{array}{l}\text { Multiple shoots after } \\
\text { eight week culture }\end{array}$ & $0.015 \pm 0.003$ & $0.051 \pm 0.007$ & $0.023 \pm 0.001$ \\
\begin{tabular}{l} 
Leaves of the plant \\
\hline
\end{tabular}
\end{tabular}

a 8-Hydroxy-9,10-diisobutyryloxy-thymol. b 10-Isobutyryloxy-8,9epoxythymyl isobutyrate. c 10-(2-Methylbutyryloxy)-8,9-epoxythymyl isobutyrate. 
antiproliferative activity of the compound against the cancer cell lines in vitro the culture is worth further studies on the optimization of the production.

\section{References}

1. Bremer K, editor. Asteraceae: cladistics \& classification. Portland, Oregon: Timber Press; 1994.

2. Englund M, Pornpongrungrueng P, Gustafsson MHG, Anderberg AA. Phylogenetic relationships and generic delimitation in Inuleae subtribe Inulinae (Asteraceae) based on ITS and cpDNA sequence data. Cladistics. 2009;25(4):319352. doi:10.1111/j.1096-0031.2009.00256.x.

3. Benešová V, Herout V, Šorm F. On terpenes CXXIV. Structure of telekin and isotelekin, new sesquiterpenic lactones from Telekia speciosa (Schreb) Baumg. Collect Czech Chem Commun. 1961;26:1350-1357.

4. Bohlmann F, Mahanta PK. Zwei neue pseudoguajanolide aus Telekia speciosa. Phytochemistry. 1979;18:887-888. doi:10.1016/0031-9422(79)80042-4.

5. Bohlmann F, Jakupovic J, Schuster A. Further eudesmanolides and xanthanolides from Telekia speciosa. Phytochemistry. 1981;20(8):1891-1893. doi:10.1016/0031-9422(81)84029-0.

6. Bohlmann F, Jakupovic J, Müller L, Schuster A. Natürlich vorkommende cyclopropenon-derivate. Angew Chem. 1981;93(3):280-281. doi:10.1002/ange.19810930314.

7. Lee JS, Min BS, Lee SM, Na MK, Kwon BM, Lee CO, et al. Cytotoxic sesquiterpene lactones from Carpesium abrotanoides. Planta Med. 2002;68(8):745-747. doi:10.1055/s-2002-33789.

8. Spiridonov NA, Konovalov DA, Arkhipov VV. Cytotoxicity of some Russian ethnomedicinal plants and plant compounds. Phytother Res. 2005;19(5):428-432. doi:10.1002/ ptr.1616.

9. Lyß G, Knorre A, Schmidt TJ, Pahl HL, Merfort I. The anti-inflammatory sesquiterpene lactone helenalin inhibits the transcription factor NF- $\kappa B$ by directly targeting p65. J Biol Chem. 1998;273(50):33508-33516. doi:10.1074/ jbc.273.50.33508.

10. Lee HT, Yang SW, Kim KH, Seo EK, Mar W. Pseudoguaianolides isolated from Inula britannica var. chinenis as inhibitory constituents against inducible nitric oxide synthase. Arch Pharm Res. 2002;25(2):151-153. doi:10.1007/BF02976555.

11. Jodynis-Liebert J, Murias M, Błoszyk E. Effect of several sesquiterpene lactones on lipid peroxidation and glutathione level. Planta Med. 1999;65(4):320-324. doi:10.1055/s-1999-13994.

12. Jodynis-Liebert J, Murias M, Błoszyk E. Effect of sesquiterpene lactones on antioxidant enzymes and some drugmetabolizing enzymes in rat liver and kidney. Planta Med. 2000;66(3):199-205. doi:10.1055/s-2000-8566.

13. Réthy B, Csupor-Löffler B, Zupkó I, Hajdú Z, Máthé I, Hohmann J, et al. Antiproliferative activity of Hungarian Asteraceae species against human cancer cell lines. Part
I. Phytother Res. 2007;21(12):1200-1208. doi:10.1002/ ptr.2240.

14. Murashige T, Skoog F. A revised medium for rapid growth and bio assays with Tobacco tissue cultures. Physiol Plant. 1962;15(3):473-497. doi:10.1111/j.1399-3054.1962. tb08052.x.

15. Bohlmann F, Niedballa U, Schulz J. Über einige Thymolderivate aus Gaillardia- und Helenium-Arten. Chem Ber. 1969;102(3):864-871. doi:10.1002/cber.19691020319.

16. Tamayo-Castillo G, Jakupovic J, Bohlmann F, Rojas A, Castro V, King RM. Germacranolides and other constituents from Ageratina species. Phytochemistry. 1988;27(9):28932897. doi:10.1016/0031-9422(88)80683-6.

17. Zee OP, Kim DK, Lee KR. Thymol derivatives from Carpesium divaricatum. Arch Pharm Res. 1998;21(5):618-620. doi:10.1007/BF02975385.

18. Mohamed KM, Mohamed MH, Ohtani K, Kasai R, Yamasaki K. Megastigmane glycosides from seeds of Trifolium alexandrinum. Phytochemistry. 1999;50(5):859-862. doi:10.1016/S0031-9422(98)00603-7.

19. Stojakowska A, Michalska K, Malarz J. Simultaneous quantification of eudesmanolides and thymol derivatives from tissues of Inula helenium and I. royleana by reversed-phase high-performance liquid chromatography. Phytochem Anal. 2006;17(3):157-161. doi:10.1002/pca.900.

20. Grass S, Zidorn C, Blattner FR, Stuppner H. Comparative molecular and phytochemical investigation of Leontodon autumnalis (Asteraceae, Lactuceae) populations from Central Europe. Phytochemistry. 2006;67(2):122-131. doi:10.1016/j.phytochem.2005.10.019.

21. Winand C, Ramaut JL, Gaspar T. Multiplication vegetative par culture in vitro d'Arnica montana L. J Pharm Belg. 1986;41:147-150.

22. Radulović N, Blagojević P, Palić P, Zlatković B. Volatiles of Telekia speciosa (Schreb.) Baumg. (Asteraceae) from Serbia. J Essent Oil Res. 2010;22:250-254.

23. Malarz J, Stojakowska A, Dohnal B, Kisiel W. Helenalin acetate in in vitro propagated plants of Arnica montana. Planta Med. 1993;59(1):51-53. doi:10.1055/s-2006-959603.

24. Schmidt TJ, Bomme U, Alfermann AW. Sesquiterpene lactone content in leaves of in vitro and field cultivated Arnica montana. Planta Med. 1998;64(3):268-270. doi:10.1055/s-2006-957423.

25. Weremczuk-Jeżyna I, Kisiel W, Wysokińska H. Thymol derivatives from hairy roots of Arnica montana. Plant Cell Rep. 2006;25(9):993-996. doi:10.1007/s00299-006-0157-y.

26. Uchiyama T, Nishimura K, Miyase T, Ueno A. Terpenoid glycosides from Picris hieracioides. Phytochemistry. 1990;29(9):2947-2951. doi:10.1016/0031-9422(90)87112-8.

27. Kim KH, Lee KH, Choi SU, Kim YH, Lee KR. Terpene and phenolic constituents of Lactuca indica L. Arch Pharm Res. 2008;31(8):983-988. doi:10.1007/s12272-001-1256-8.

28. Otsuka H, Takeda Y, Yamasaki K, Takeda Y. Structural elucidation of dendranthemosides A and B: two new beta-ionone glucosides from Dendranthema shiwogiku. Planta Med. 1992;58(4):373-375. doi:10.1055/s-2006-961489. 